\title{
1 Assessment and Speciation of Chlorine Demand in Fresh-Cut Produce Wash Water
}

2 ShihChi Weng ${ }^{1}$, Yaguang $\mathrm{Luo}^{2}, \mathrm{Jie} \mathrm{Li}^{2,3}$, Bin Zhou ${ }^{2}$, Joseph G. Jacangelo ${ }^{1,4,5}$, Kellogg J.

3 Schwab $^{1,5^{*}}$

$4{ }^{1}$ JHU/MWH Alliance, 615 N. Wolfe St., Johns Hopkins University, Baltimore, MD 21205

$5 \quad{ }^{2}$ Food Quality, and Environmental Microbial and Food Safety Laboratories, U.S. Department of

6 Agriculture, Agriculture Research Service, 10300 Baltimore Ave, Beltsville, MD 20705

$7 \quad{ }^{3}$ College of Food Science and Technology, Huazhong Agricultural University, Wuhan, P. R.

8 China, 430070

$9 \quad{ }^{4}$ MWH Global Inc., 300 North Lake Avenue, Pasadena, CA 91101

$10{ }^{5}$ Department of Environmental Health Sciences, Johns Hopkins University Bloomberg School of

11 Public Health, 615 N. Wolfe St., Baltimore, MD 21205; E-mail kschwab1@jhu.edu, Phone

12 number: +1(410) 614-5753 


\section{Abstract}

14 For the fresh-cut produce industry, a critical area of concern is potential pathogen

15 cross-contamination during wash operations when wash water is reused and re-circulated

16 in wash systems continuously imputed with fresh-cut produce. However, little research

17 has focused on the chemical properties of wash water. Organic input from residual soil

18 and vegetable material deteriorates water quality and creates increasing chlorine demand

19 within this wash water.

20 This study evaluated the origins of chlorine demand input and chlorine decay kinetics

21 of fresh-cut produce wash water. Using a model system, vegetable juice released per $\mathrm{kg}$

22 of processed produce for shredded romaine lettuce, shredded iceberg lettuce, shredded

23 carrot and baby spinach was $82.1 \mathrm{~mL} / \mathrm{kg}, 94.5 \mathrm{~mL} / \mathrm{kg}, 158 \mathrm{~mL} / \mathrm{kg}$, and $2.26 \mathrm{~mL} / \mathrm{kg}$,

24 respectively. Batch water analysis revealed a rapid reaction between constituents in the

25 wash water and chlorine where over a 90 minute observation period, $50 \%$ of chlorine

26 demand occurred within first 5 minutes, underscoring the challenge for any water

27 treatment process to reduce chlorine demand once vegetables are deposited into washing

28 systems. Moreover, the results also showed sustained chlorine demand over 90-minute

29 periods, indicating an accumulative effect on chlorine consumption with continuous

30 organic input. Additionally, HPLC-SEC analysis showed that the constituents 
31 contributing to chlorine demand are predominantly dissolved small molecules $(<3400$

$32 \mathrm{Da}$ ), which will challenge water reuse treatment approaches. This study provides

33 quantitative information of chlorine demand origins and chlorine decay kinetics in wash

34 water and provides baseline data critical for integrating water reuse in the fresh produce

35 processing industry.

36

37 Key Words: Fresh-cut produce, wash water, chlorination, chlorine demand 


\section{Introduction}

39 The demand of fresh-cut leafy green vegetables has continued to expand as

40 consumers have integrated healthy diets with the concept of ready to eat meals. Reports

41 by the World Health Organization (WHO, 2005) document that consumption of

42 vegetables has benefits to human health by providing high levels of minerals and

43 vitamins with the goal of preventing chronic diseases. Consuming uncooked food,

44 however, has risks, such as those associated with food-borne illness outbreaks. As

45 outlined by Center for Food Safety and Applied Nutrition, 72 outbreaks were reported to

46 be associated with fresh produce from 1996 to 2006 with 18 out of these outbreaks due to

47 fresh-cut produce (CFSAN, 2008). Additional outbreak investigations conducted in

48 recent years continue to indicate that consumption of contaminated fresh-cut produce can

49 be problematic (Greene et al., 2008; Nygård et al., 2008; Söderström et al., 2008;

50 Hanning et al., 2009; Barton Behravesh et al., 2011; Buchholz et al., 2011; MacDonald et

51 al., 2012). To reduce microbial contamination and improve produce safety, it is clear that

52 proper sanitation is essential during fresh-cut produce postharvest processing. In the

53 absence of a practical decontamination method to directly remove/kill pathogens from

54 produce, washing with sanitizing water has been widely adopted by the fresh produce

55 food industry. Although other disinfectants or disinfection methods such as ozone, 
56 organic acids, chlorine dioxide, and UV irradiation have been used (Gil et al., 2009;

57 Ölmez and Kretzschmar, 2009), addition of chlorine (or other forms of hypochlorous acid)

58 in wash water is still the most common practice. Chlorine is predominant because of its

59 efficacious disinfection capability against a wide spectrum of microorganisms and its

60 economic accessibility compared to other disinfectants (Arana et al., 1999;

61 Corona-Vasquez et al., 2002; Li et al., 2002; Bohrerova and Linden, 2006; Baxter et al.,

62 2007; Luh and Mariñas, 2007; Cromeans et al., 2010)

63 The vegetable washing process in food processing facilities is a mechanism by which

64 water-borne pathogens can be dispersed throughout wash water. Allende et al. (2008)

65 reported that pathogens could carry over from previous processed produce to a

66 subsequent batch of produce via wash water if insufficient residual chlorine is maintained

67 in the washing tank. Luo et al. (2011) also described the importance of maintaining a

68 minimum chlorine level during the wash process to avoid cross-contamination. However,

69 during washing of fresh-cut produce, large amounts of organic compounds from soil

70 debris and from exudates of produce are deposited into wash water (Luo et al., 2012). As

71 these compounds react with chlorine, there is a rapid decrease in the level of free

72 available chlorine as well as the potential generation of disinfection byproducts (Chen $e t$

73 al., 2010; López-Gálvez et al., 2010). Although chlorine replenishment is practiced 
74 during commercial produce washing operations, the level of organic compounds

75 generated during continuous produce feeding rapidly deteriorates wash water quality in

76 terms of depletion of chlorine and increasing turbidity and chemical oxygen demand (Luo

77 et al., 2012). Maintaining adequate residual chlorine levels in the washing tank is

78 challenging in commercial produce wash processes, and the resulting low chlorine level

79 often increases the risk of cross-contamination (Luo et al., 2012).

80 Previous studies have predominantly focused on the association between water

81 quality and the potential of cross contamination (Allende et al., 2008; Luo et al., 2011;

82 Van Haute et al., 2013). Minimal information is available regarding quantitative

83 assessment of the fraction of wash water responsible for observed chlorine demand,

84 particularly in regards to organic loading. Therefore, this study evaluated the organic

85 input per unit of processed produce during a washing process by using chemical

86 properties (e.g., chemical oxygen demand or total organic carbon) of wash water from

87 four different vegetables (romaine lettuce, iceberg lettuce, carrots, and baby spinach). The

88 data generated is useful in terms of estimating the quantity of chlorine demand input per

89 mass of vegetable following different produce processing techniques. Moreover, the

90 assessment of chlorination kinetics of these vegetable wash waters was conducted to

91 characterize the behavior of chlorine demand in terms of reaction time and chloramine 
92 formation. By generating these data, existing and alternative industrial raw vegetable

93 wash water processes should be able to be evaluated for the best treatment strategy.

94 Further, use of this information could enable conceptual engineering designs for safe

95 water reuse during leafy green washing processes.

\section{2. Materials and Methods}

\section{$97 \quad 2.1$ Vegetable Wash Water and Vegetable Extracts}

98 Romaine lettuce (Lactuca sativa L.), iceberg lettuce (Lactuca sativa), and carrots

99 (Daucus carata L.) were purchased from a wholesale market located in Baltimore, MD.

100 Fresh-cut samples were prepared freshly on the same day that experiments were

101 conducted by shredding $\left(0.32 \mathrm{~cm}\right.$ in width) or chopping $\left(6.45 \mathrm{~cm}^{2}\right)$ for both romaine

102 lettuce and iceberg lettuce and shredding $(0.32 \mathrm{~cm}$ by $0.32 \mathrm{~cm})$ or slicing $(0.32 \mathrm{~cm}$ in

103 thickness) for carrots using a commercial food slicer (ECD-302; Nichimo International

104 Inc., WA ). Freshly harvested baby spinach leaves were received from Taylor Farms

105 (Jessup, MD) and were processed without cutting.

106 Washing experiments were conducted by submerging prepared produce in a washing

107 tank containing sterile deionized water at a produce:water ratio of $1 \mathrm{~kg}: 20 \mathrm{~L}$ for prepared

108 romaine lettuce, iceberg lettuce, and baby spinach samples and a ratio of $1 \mathrm{~kg}: 40 \mathrm{~L}$ for 
109 prepared carrot samples at room temperature $\left(22^{\circ} \mathrm{C}\right)$. During each simulated wash cycle,

$1101 \mathrm{~kg}$ of prepared produce sample was packed in a mesh bag and completely submerged

111 into washing tank for 1 minute. The romaine lettuce, iceberg lettuce, and baby spinach

112 were processed for a total of 15 simulated wash cycles and the carrots for 10 simulated

113 wash cycles. A new batch of prepared produce was used for each simulated wash cycle

114 and additional fresh water was added as needed to maintain a fixed volume between

115 simulated wash cycles, which simulated the continuous operation in a commercial setting.

116 Thus, a batch of $15 \mathrm{~kg}$ of produce was used in total during washing experiments for

117 romaine lettuce, iceberg lettuce, and baby spinach and $10 \mathrm{~kg}$ in total during washing

118 experiments for carrots. Samples were collected at the end of experiment or as needed

119 between simulated wash cycles.

120 Vegetable liquid exacts of all four vegetables were prepared following the method of

121 Shen et al. (2012) with a commercial household juice maker (Breville Model BJE200XL

122 Juice Fountain, Shanghai, China). The liquid portion was collected, filtered with

123 cheesecloth to remove coarse vegetable fragments and stored at $-20{ }^{\circ} \mathrm{C}$ until use.

\section{$124 \quad 2.2$ Analytical methods}

125 Samples from washing experiments and from vegetable extracts were prepared with

126 a proper dilution ratio to fit the detection range of analytical methods. The analysis 
127 included chemical oxygen demand (COD) by colorimetric method (method 5220;

128 APHA-AWWA-WEF (2012)) using the TNT 822 COD Kit (Hach Company, CO),

129 nitrogen composition analysis by colorimetric method using TNT 880 simplified TKN kit

130 (Hach Company, CO), total organic carbon (TOC) by persulfate-ultraviolet oxidation

131 method (Method 5310; APHA-AWWA-WEF (2012)) using a Sievers 900 series TOC

132 analyzer (GE Analytical Instrument, CO), ultraviolet light absorbance at wavelength of

$133254 \mathrm{~nm}\left(\mathrm{UV}_{254}\right.$ abs.) using a DR4000U spectrophotometer (Hach Company, CO), and

134 anions analysis by IC25 ion chromatography system with IonPac@ A17 column (Thermo

135 Scientific, CA).

$136 \quad 2.3$ Chlorination Experiments

137 The final wash water samples were collected from washing experiments using four

138 vegetable types as described above and were subjected to chlorination where $1 \mathrm{~mL}$ of

139 sample was mixed with $0.02 \mathrm{~mL}$ of diluted chlorine stock solution $(80000-8000 \mathrm{mg} / \mathrm{L}$ as

$\left.140 \mathrm{Cl}_{2}\right)$ in form of sodium hypochlorous acid ( $\mathrm{NaOCl}, 10-15 \%$, Sigma-Aldrich). The applied

141 chlorine concentration varies from 1600 to $160 \mathrm{mg} / \mathrm{L}$ as $\mathrm{Cl}_{2}$ based on the chlorine demand

142 in various wash waters and the feasibility for analysis by selected methods. Time-course

143 sampling was conducted over sequential 90 minute periods to assess the rate of chlorine

144 consumption and chloramine formation. Chlorine demand was calculated by subtracting 
145 the chlorine consumption in the blank sample (deionized water) from the chlorine

146 consumption in wash water samples. During chlorination experiments, a pH of 7.0 was

147 maintained by addition of phosphate buffer $(50 \mathrm{mM})$ as needed. The

$148 \mathrm{~N}, \mathrm{~N}$-diethyl-p-phenylene diamine (DPD) colorimetric method (APHA-AWWA-WEF,

149 2012) was used to measure residual chlorine and total chlorine; chloramine formation

150 was calculated by subtracting the residual chlorine reading from total chlorine

151 measurement. Samples from chlorination experiments were collected and diluted with

152 deionized water at a proper ratio according to the applied dose to accommodate the best

153 detection range of the analytical method for chlorine and chloramine measurements. The

154 effects of filtration on reduction of chlorine demand and chloramine formation were also

155 evaluated and the filtered samples were prepared by using a $0.45 \mu \mathrm{m}$ pore size filter

156 (PVDF; Fisher Scientific, PA). Moreover, the effects of numbers of wash cycles were also

157 evaluated with shredded iceberg lettuce following 5, 10, and 15 washing cycles.

158 The analysis of HPLC-Size Exclusion Chromatography (HPLC-SEC; Ultimate 3000

159 system; Thermo Scientific, CA) equipped with BioSep-SEC-S3000 column (300 mm $\times$

$1607.8 \mathrm{~mm}$; Phenomenex, CA) was applied on the final wash water samples from four

161 vegetables with/without chlorination. The mobile phase was a mixture of $4.0 \mathrm{mM}$

162 phosphate buffer solution and $0.1 \mathrm{M}$ sodium sulfate solution with a flow rate of 1.054 
$163 \mathrm{~mL} / \mathrm{min}$, isocratic. All samples for HPLC-SEC were filtered with $0.45 \mu \mathrm{m}$ pore size filter

164 (PVDF; Fisher Scientific, PA) before analysis to prevent clogging in HPLC columns.

\section{3. Results and Discussion}

\section{3.1 Assessment of Vegetable Wash}

167 Table 1 shows COD, nitrogen composition, $\mathrm{TOC}, \mathrm{UV}_{254}$ absorbance, and anion

168 measurements of four vegetable extracts and wash water of three shredded vegetables

169 (romaine lettuce, iceberg lettuce and carrot) and baby spinach. Chopped and sliced

170 produce samples had less vegetable exudate compared to shredded vegetables resulting in

171 less of an issue for wash water processing and thus were not further evaluated (data not

172 shown). From Table 1, the results reveal that wash water from carrots contained high

173 concentrations of COD and TOC, but low concentrations of nitrogen, compared to

174 romaine lettuce and iceberg lettuce. For wash waters and vegetable extracts, an

175 Equivalent Extract Ratio (EER) (\%, volume/volume) was calculated by the measurement

176 of water quality parameters (e.g., COD and TOC) of vegetable wash water divided by the

177 same measurements on vegetable extracts. This ratio represents the percentage of a

178 diluted vegetable extract solution that contains the same amount of target constituents as

179 present in wash water. The average and standard deviation of equivalent extract ratio for

180 four vegetable wash waters are shown in Table 2. Outlier measurements potentially 
181 resulting from extraneous soil debris were excluded from data analysis where the outlier

182 measurement was defined as greater than three times the standard deviation.

183 The equivalent volume of vegetable juice released per weight of processed produce

184 was calculated based on equivalent extract ratio, volume of wash water, and mass of total

185 processed produce, as shown in Equation 1.

$$
\begin{aligned}
& \text { Equivalent Vegetable Juice Released }\left(\frac{\mathrm{mL}}{\mathrm{kg}}\right) \\
& =\frac{\text { Average of Equivalent Juice Ratio }(\%) \times \text { Volume of Wash Water }(\mathrm{mL})}{\text { Total Mass of Processed Produce }(\mathrm{kg})}
\end{aligned}
$$

186 Table 1 and Table 2 reveal that baby spinach wash water has the lowest equivalent

187 extract ratio, which could be due to the whole-plant being washed as compared to the

188 other vegetables that were chopped or shredded. Minimal vegetable juice was recovered,

189 only $2.26 \mathrm{~mL}$ per $\mathrm{kg}$ of processed produce. Wash waters from the other three shredded

190 vegetable washes contained much higher concentrations of targeted analytes and

191 increased release of vegetable juice compared to baby spinach wash waters, $82.1 \mathrm{~mL} / \mathrm{kg}$

192 for romaine lettuce, $94.5 \mathrm{~mL} / \mathrm{kg}$ for iceberg lettuce, and $158 \mathrm{~mL} / \mathrm{kg}$ for carrots. Enhanced

193 release of vegetable juice resulted from increased vegetable tissue surface area due to

194 cutting or shredding. Nou and Luo (2010) have proposed washing whole-leaf produce to 
195 reduce the rate of water quality deterioration during the washing process with a

196 subsequent reduction in potential microbial cross-contamination.

197 The analysis of vegetable juice released during the wash process provides

198 information regarding organic loading into wash water. Zhou et al. (2014) established an

199 empirically-based equation to calculate the chlorine requirement for vegetable wash, but

200 the equation was established based on the vegetable extracts, not the amount of processed

201 produce. Our study provides quantitative information on the volume of vegetable fluid

202 extracts released by washing per unit of produce, which can be used in the empirical

203 algorithm equation to calculate chlorine demand based on the amount of processed

204 produce.

$205 \quad 3.2$ Chlorination Kinetics of Vegetable Wash

206 Chlorine demand of wash water from three vegetables (romaine lettuce, iceberg

207 lettuce and carrots) following two different cutting techniques (chopped and shredded) as

208 well as from whole baby spinach was evaluated at $\mathrm{pH} 7.0$ with time-course sampling over

20990 minutes. In addition, the behavior of chloramine formation was also evaluated. The

210 results are reported in Figure 1. Shredded-vegetable wash water had higher chlorine

211 demand than chopped/sliced-vegetable wash water due to increased exposure of

212 vegetable tissue generated by shredding compared to chopping/slicing, resulting in 
213 enhanced vegetable juice release. As shown in Figure 1, wash water from shredded

214 carrots had the highest chlorine demand. This is consistent with the data in Table 1 and

215 Table 2 where the wash water from shredded carrots had the highest COD and TOC and

216 the largest volume of vegetable juice released per mass of processed produce among four

217 vegetables that were analyzed.

218 Figure 1 also shows rapid chlorine consumption and fast chloramine formation

219 following chlorination of all four vegetable wash waters. Over a 90 minute observation

220 period, $50 \%$ of chlorine demand occurred within the first 5 minutes, except wash water

221 from baby spinach (47\%), as shown in Figure 2. Chloramine formation, which includes

222 both organic chloramines and inorganic chloramines, was almost complete within 5

223 minutes for all four vegetable wash waters with only modest increases in chloramine

224 concentration observed subsequent to this time period. These results are consistent with

225 previous findings in the literature. Deborde and von Gunten (2008), for example,

226 reported that chlorination of nitrous compounds involves an electrophilic substitution

227 reaction, where a chloride atom substitutes a hydrogen atom on amine functional group

228 and results in rapid formation of chloramines.

229 Effects of filtration $(0.45 \mu \mathrm{m})$ on reduction of chlorine demand and chloramine

230 formation were also evaluated. Filtration has been integrated into water treatment settings 
231 for decades and has shown high efficiency to remove solids from water. (Zularisam et al.,

232 2006) Moreover, Nelson et al. (2007) investigated the application of a submerged

233 membrane microfiltration system in a fresh-cut vegetable washing operation and showed

234 high removal of particles and total solids. However, our results demonstrated a low

235 efficiency for filtration to reduce chlorine demand of wash waters from iceberg lettuce,

236 romaine lettuce and carrots following two different cutting techniques (chopped and

237 shredded), ranging from $4.7 \%$ to $25.9 \%$ after 90 minutes contact time (black bars in

238 Figure 3). This modest reduction was most likely due to removal of chlorine demand

239 originating from coarse particles, such as pieces of vegetable tissue. The results indicate

240 that among these three vegetable wash waters, most of the chlorine demand comes from

241 dissolved compounds, not from particles, with the dissolved compounds mostly generated

242 by the release of vegetable juice during washing. This result is consistent with the finding

243 of Van Haute et al. (2015), where little or no dissolved organic was removed by removing

244 particles (turbidity). Moreover, the reduction of chloramine formation by filtration is

245 higher than removal of chlorine demand, ranging from $12.1 \%$ to $43.7 \%$ among three

246 vegetable wash waters (grey bars, Figure 3).

247 Interestingly, the highest chlorine demand removal efficiency and chloramine

248 formation following filtration is found in baby spinach wash water; $37.6 \%$ and $59.2 \%$, 
249 respectively (Figure 3). These results are most likely due to whole-leaf washing applied

250 to baby spinach. A greater portion of chlorine demand in whole-leaf wash water comes

251 from foreign compounds (e.g., soil) than in fresh-cut vegetable wash water. Those foreign

252 compounds were usually induced in the form of small solids that could be removed by

253 filtration.

254 Data from Table 1 and Figure 2 were analyzed for correlations among water quality

255 parameters and chlorine demand for four vegetables. Among all parameters which were

256 examined in this study, the concentrations of COD and TOC in wash water had the best

257 linear correlations with chlorine demand, as shown in Table 3. The high correlation

258 between COD and chlorine demand can be explained in part because the COD

259 concentration represents the concentration of compounds that could be chemically

260 oxidized and chlorine is a strong oxidant available to oxidize those compounds

261 contributing to COD. Moreover, since organic compounds are the major source of COD

262 in wash water, the high correlation between TOC and chlorine demand is expected. The

263 third highest correlation is between chlorine demand and $\mathrm{UV}_{254}$ absorbance (a standard

264 water quality parameter analyzed in drinking water). $\mathrm{UV}_{254}$ absorbance is used to

265 estimate organic content., Compounds with $\mathrm{UV}_{254}$ absorbance, however, only represent

266 part of organic wash water content, resulting in a slightly lower correlation of $\mathrm{UV}_{254}$ 
267 absorbance than of COD or TOC. These results imply that the concentration of COD and

268 TOC could be used as indicators for chlorine demand during washing process with an

269 online real-time monitoring system.

270 Additionally, the effects of the number of simulated wash cycles on chlorination

271 kinetics and chloramine formation were also evaluated. Romaine lettuce was selected as

272 the target vegetable and washing experiments were conducted as described above. Water

273 samples were collected after the $5^{\text {th }}, 10^{\text {th }}$ and $15^{\text {th }}$ simulated wash cycle, and these

274 samples underwent chlorination experiments in triplicate to assess chlorine demand and

275 chloramine formation. With increasing numbers of simulated wash cycles, chlorine

276 demand increased (Figure 4(a)), as did chloramine formation (Figure 4(b)). The behavior

277 of chlorination kinetics over 90 minutes was consistent among three different numbers of

278 simulated wash cycles; 59.6-64.5\% of chlorine demand had been fulfilled within 5 min

279 contact time with chlorine. Moreover, the efficiency of chlorine demand removal by

280 filtration is similar $(18.1 \%, 17.4 \%$, and $19.7 \%$ for 5 simulated wash cycles, 10 simulated

281 wash cycles, and 15 simulated wash cycles, respectively). Since demand was caused by

282 chlorine-demanding substances in wash water, our results indicate that more of these

283 substances were induced into wash water from vegetables with higher number of

284 simulated wash cycles, which could be translated to the amount of processed vegetables. 
285 Our results were consistent with the observation by Luo (2007) that concentrations of

286 COD and turbidity had a positive correlation with the mass of processed produce.

\section{3.3 Changes to Wash Water Quality after Chlorination}

288 HPLC-SEC analysis separates compounds based on molecular size resulting in the

289 ability to identify groups of compounds with specific molecular weights by comparing

290 the target analyte with the retention time of a series of standardized compounds

291 (polystyrenesulfonic acid sodium salt; Fluka) with a known molecular weight. This

292 method has been used to study natural organic matter which is known to contribute to

293 TOC and to be a source of chorine demand in drinking water (Her et al., 2002; Chow et

$294 a l ., 2008)$. In this study, HPLC-SEC was applied on vegetable wash water to evaluate

295 which group of compounds contributes to chlorine demand based on molecular weight.

296 The HPLC-SEC chromatographs from wash waters from four vegetables with/without

297 chlorination were compared, and the results are shown in Figure 5. The majority of

298 compounds in four wash waters have molecular weights around 4300 or less (Figure S1

299 in Supporting Material). The differences in chromatographs from samples with and

300 without chlorination reveal compounds in wash water that had been modified by chlorine.

301 Among four vegetables, the minimum chromatographic difference was observed with

302 spinach wash water, due to the low chlorine demand. On the other hand, wash water from 
303 romaine lettuce showed the largest change in chromatographs before and after

304 chlorination. These results indicate a large composition change by chlorine which is

305 consistent with our previous observation of high chlorine demand in romaine lettuce

306 wash water. Although wash water from carrots and iceberg lettuce also presented high

307 chlorine demand, there were only moderate changes in chromatographs before and after

308 chlorination, indicating most of the compounds structurally did not change. The results

309 suggest that chlorine, which was consumed, underwent only electrophilic substitution,

310 instead of completely degrading the compounds (Deborde and von Gunten, 2008).

311 Nevertheless, a portion of compounds in iceberg lettuce and carrot wash waters were

312 degraded to smaller molecular weight compounds after chlorination, as shown in a hump

313 at the right side of the main peaks. The HPLC-SEC results show the fraction of

314 compounds that contribute to chlorine demand which could facilitate development of

315 treatment process that specifically target interfering substances within this fraction. It is

316 important to note that our results represent the change of compounds with absorbance

317 only at wavelength of $254 \mathrm{~nm}$, which does not represent all constituents in wash water.

318 A comprehensive study with multi-wavelength (or more detail compound separation)

319 would be necessary for complete molecular-weight-based chlorine demand profiling.

320 These findings indicate that $\mathrm{UV}_{254}$ absorbance is not the only parameter that should be 
321 used to evaluate the chlorine demand. From Table 3, the correlation between chlorine

322 demand and $\mathrm{UV}_{254}$ absorbance is 0.73 , which indicates $\mathrm{UV}_{254}$ absorbance is not a perfect

323 parameter to predict chlorine demand. Other parameters need to be considered (e.g., COD

324 and TOC). This information is particularly useful when integrating membrane filtration

325 with certain molecular weight cutoffs as a treatment option for chlorine demand removal

326 during the wash process or for reuse of wash water.

\section{4. Conclusion}

328 Fundamental studies of the characteristics of vegetable wash water are necessary for

329 fresh-cut produce industry to thoroughly understand the impact of water quality on the

330 efficacy of its washing processes. The characteristics of a target water quality are

331 essential for selecting a feasible treatment system (Johns, 1995). As such, our study

332 estimated the rate of constituents entering the wash water in terms of volume of vegetable

333 juice per unit mass of processed produce. This information could be used to estimate

334 chlorine demand in conjunction with an existing model (Zhou et al., 2014). Moreover,

335 this study assessed the chemical properties of produce wash water with a focus on how

336 selected water quality parameters affected chlorination. TOC and COD showed good

337 correlations to chlorine demand regardless of the type of vegetables; consequently, these

338 two parameters have the potential to estimate the amount of chlorine required during 
339 washing process. Additionally, SEC results showed changes in molecular weight of the

340 fractions of constituents after chlorination, such changes lend insight into the molecular

341 weight fractions that contribute to the overall chlorine demand of wash water.

342 The desired outcome is development of an approach that will reduce chlorine

343 demand, thus enabling adequate residual chlorine levels to prevent cross-contamination

344 during the entire wash cycle process. The results from this study showed a fast reaction

345 between constituents in wash water and chlorine among four target vegetables. These

346 interactions will be a challenge for any water treatment process designed to reduce

347 chlorine demand once the constituents enter a chlorinated washing basin. From an

348 engineering aspect, the alternative solution is to reduce organic loading input, potentially

349 by having a chlorinated pre-wash or rinse for fresh-cut vegetables or by first having

350 whole-leaf washes (Nou and Luo, 2010).

351 Substantial quantities of water are used for various purposes during food processing

352 (Poretti, 1990; Dupont and Renzetti, 1998; Fähnrich et al., 1998). Due to the large

353 volume used, wash water is becoming significant economic and environmental issues for

354 fresh produce industry, especially when many areas in the U.S. are experiencing water

355 shortages and severe droughts. Despite the limitations and challenges from regulatory and

356 treatment technologies (Casani et al., 2005), many factors (e.g., economical and 
357 environmental ones) have driven food industry to expand the scale of water reuse. Our

358 study provides information for engineering design of water treatment for water reuse and

359 has implications for future development of treatment strategies for fresh-cut produce

360 industry.

\section{ACKNOWLEDGEMENTS}

362 This work is supported by USDA-NIFA Specialty Crop Research Initiative Grant

363 Award No. 2010-51181-21230, the MWH/JHU Alliance, The Hopkins Water Institute,

364 and the Osprey Foundation of Maryland. We would like to thank Jason Bishai for

365 technical laboratory support and Taylor Farm for providing experimental material.

\section{References}

367 1. Allende, A., Selma, M.V., López-Gálvez, F., Villaescusa, R., Gil, M.I., 2008. Impact

368 of Wash Water Quality on Sensory and Microbial Quality, Including Escherichia coli

369 Cross-Contamination, of Fresh-Cut Escarole. Journal of Food Protection 71,

$370 \quad 2514-2518$.

371 2. APHA-AWWA-WEF, 2012. Standard Methods for the Examination of Water and

372 Wastewater. (22th ed.). Washington. DC.

373 3. Arana, I., Santorum, P., Muela, A., Barcina, I., 1999. Chlorination and ozonation of

374 waste-water: comparative analysis of efficacy through the effect on Escherichia coli 
375 membranes. Journal of Applied Microbiology 86, 883-883.

376 4. Barton Behravesh, C., Mody, R.K., Jungk, J., Gaul, L., Redd, J.T., Chen, S.,

377 Cosgrove, S., Hedican, E., Sweat, D., Chávez-Hauser, L., Snow, S.L., Hanson, H.,

378 Nguyen, T.-A., Sodha, S.V., Boore, A.L., Russo, E., Mikoleit, M., Theobald, L.,

379 Gerner-Smidt, P., Hoekstra, R.M., Angulo, F.J., Swerdlow, D.L., Tauxe, R.V., Griffin,

380 P.M., Williams, I.T., 2011. 2008 Outbreak of Salmonella Saintpaul Infections

381 Associated with Raw Produce. New England Journal of Medicine 364, 918-927.

382 5. Baxter, C., Hofmann, R., Templeton, M., Brown, M., Andrews, R., 2007.

383 Inactivation of Adenovirus Types 2, 5, and 41 in Drinking Water by UV Light, Free

384 Chlorine, and Monochloramine. Journal of Environmental Engineering 133, 95-103.

385 6. Bohrerova, Z., Linden, K.G., 2006. Ultraviolet and Chlorine Disinfection of

386 Mycobacterium in Wastewater: Effect of Aggregation. Water Environment Research

$387 \quad 78,565-571$.

388 7. Buchholz, U., Bernard, H., Werber, D., Böhmer, M.M., Remschmidt, C., Wilking, H., 389 Deleré, Y., an der Heiden, M., Adlhoch, C., Dreesman, J., Ehlers, J., Ethelberg, S.,

390 Faber, M., Frank, C., Fricke, G., Greiner, M., Höhle, M., Ivarsson, S., Jark, U.,

391 Kirchner, M., Koch, J., Krause, G., Luber, P., Rosner, B., Stark, K., Kühne, M., 2011.

392 German Outbreak of Escherichia coli O104:H4 Associated with Sprouts. New 
393 England Journal of Medicine 365, 1763-1770.

394 8. Casani, S., Rouhany, M., Knøchel, S., 2005. A discussion paper on challenges and

395 limitations to water reuse and hygiene in the food industry. Water Research 39,

$396 \quad 1134-1146$.

397 9. CFSAN, 2008. Guidance for Industry: Guide to Minimize Microbial Food Safety

398 Hazards of Fresh-cut Fruits and Vegetables., U.S. Department of Health and Human

399 Services Food and Drug Administration Center for Food Safety and Applied

$400 \quad$ Nutrition (CFSAN). Available at

401

http://www.fda.gov/Food/GuidanceRegulation/GuidanceDocumentsRegulatoryInfor

402

mation/ProducePlantProducts/ucm064458.htm\#ch10, Accessed 08.09.2014.

403 10. Chen, Z., Zhu, C., Zhang, Y., Niu, D., Du, J., 2010. Effects of aqueous chlorine

404 dioxide treatment on enzymatic browning and shelf-life of fresh-cut asparagus

405 lettuce (Lactuca sativa L.). Postharvest Biology and Technology 58, 232-238.

406 11. Chow, C.W.K., Fabris, R., Leeuwen, J.v., Wang, D., Drikas, M., 2008. Assessing

407 Natural Organic Matter Treatability Using High Performance Size Exclusion

408 Chromatography. Environmental Science \& Technology 42, 6683-6689.

409 12. Corona-Vasquez, B., Samuelson, A., Rennecker, J.L., Mariñas, B.J., 2002.

410 Inactivation of Cryptosporidium parvum oocysts with ozone and free chlorine. 
$411 \quad$ Water Research 36, 4053-4063.

412 13. Cromeans, T.L., Kahler, A.M., Hill, V.R., 2010. Inactivation of Adenoviruses,

413 Enteroviruses, and Murine Norovirus in Water by Free Chlorine and

414 Monochloramine. Applied and Environmental Microbiology 76, 1028-1033.

415 14. Deborde, M., von Gunten, U., 2008. Reactions of chlorine with inorganic and

416 organic compounds during water treatment-Kinetics and mechanisms: A critical

417 review. Water Research 42, 13-51.

418 15. Dupont, D., Renzetti, S., 1998. Water Use in the Canadian Food Processing Industry.

419 Canadian Journal of Agricultural Economics/Revue canadienne d'agroeconomie 46,

$420 \quad 83-92$

421 16. Fähnrich, A., Mavrov, V., Chmiel, H., 1998. Membrane processes for water reuse in

422 the food industry. Desalination 119, 213-216.

423 17. Gil, M.I., Selma, M.V., López-Gálvez, F., Allende, A., 2009. Fresh-cut product

424 sanitation and wash water disinfection: Problems and solutions. International Journal

425 of Food Microbiology 134, 37-45.

426 18. Greene, S.K., Daly, E.R., Talbot, E.A., Demma, L.J., Holzbauer, S., Patel, N.J., Hill,

427 T.A., Walderhaug, M.O., Hoekstra, R.M., Lynch, M.F., Painter, J.A., 2008.

428 Recurrent multistate outbreak of Salmonella Newport associated with tomatoes from 
429 contaminated fields, 2005. Epidemiology \& Infection 136, 157-165.

430 19. Hanning, I.B., Nutt, J.D., Ricke, S.C., 2009. Salmonellosis Outbreaks in the United

431 States Due to Fresh Produce: Sources and Potential Intervention Measures.

$432 \quad$ Foodborne Pathogens and Disease 6, 635-648.

433 20. Her, N., Amy, G., Foss, D., Cho, J., Yoon, Y., Kosenka, P., 2002. Optimization of

434 Method for Detecting and Characterizing NOM by HPLC-Size Exclusion

435 Chromatography with UV and On-Line DOC Detection. Environmental Science \&

$436 \quad$ Technology 36, 1069-1076.

437 21. Johns, M.R., 1995. Developments in wastewater treatment in the meat processing

438 industry: A review. Bioresource Technology 54, 203-216.

439 22. Li, J.W., Xin, Z.T., Wang, X.W., Zheng, J.L., Chao, F.H., 2002. Mechanisms of

$440 \quad$ Inactivation of Hepatitis A Virus by Chlorine. Applied and Environmental

$441 \quad$ Microbiology 68, 4951-4955.

442 23. López-Gálvez, F., Allende, A., Truchado, P., Martínez-Sánchez, A., Tudela, J.A.,

443 Selma, M.V., Gil, M.I., 2010. Suitability of aqueous chlorine dioxide versus sodium

444 hypochlorite as an effective sanitizer for preserving quality of fresh-cut lettuce while

445 avoiding by-product formation. Postharvest Biology and Technology 55, 53-60.

446 24. Luh, J., Mariñas, B.J., 2007. Inactivation of Mycobacterium avium with Free 
448 25. Luo, Y., 2007. Fresh-cut Produce Wash Water Reuse Affects Water Quality and

449 Packaged Product Quality and Microbial Growth in Romaine Lettuce. HortScience $450 \quad 42,1413-1419$.

451 26. Luo, Y., Nou, X., Millner, P., Zhou, B., Shen, C., Yang, Y., Wu, Y., Wang, Q., Feng,

452 H., Shelton, D., 2012. A pilot plant scale evaluation of a new process aid for

453 enhancing chlorine efficacy against pathogen survival and cross-contamination

454 during produce wash. International Journal of Food Microbiology 158, 133-139.

455 27. Luo, Y., Nou, X., Yang, Y., Alegre, I., Turner, E., Feng, H., Abadias, M., Conway, W., 456 2011. Determination of Free Chlorine Concentrations Needed To Prevent

457 Escherichia coli O157:H7 Cross-Contamination during Fresh-Cut Produce Wash.

$458 \quad$ Journal of Food Protection 74, 352-358.

459 28. MacDonald, E., Heier, B.T., Nygard, K., Stalheim, T., Cudjoe, K.S., Skjerdal, T.,

460 Wester, A.L., Lindstedt, B.A., Stavnes, T.L., Vold, L., 2012. Yersinia enterocolitica

461 outbreak associated with ready-to-eat salad mix, Norway, 2011. Emerging infectious

462 diseases 18, 1496-1499.

463 29. Nelson, H., Singh, R., Toledo, R., Singh, N., 2007. The Use of a Submerged

464 Microfiltration System for Regeneration and Reuse of Wastewater in a Fresh-cut 
30. Nou, X., Luo, Y., 2010. Whole-Leaf Wash Improves Chlorine Efficacy for Microbial

467 Reduction and Prevents Pathogen Cross-Contamination during Fresh-Cut Lettuce

468 Processing. Journal of Food Science 75, M283-M290.

469 31. Nygård, K., Lassen, J., Vold, L., Andersson, Y., Fisher, I., Löfdahl, S., Threlfall, J.,

470 Luzzi, I., Peters, T., Hampton, M., Torpdahl, M., Kapperud, G., Aavitsland, P., 2008.

471 Outbreak of Salmonella Thompson Infections Linked to Imported Rucola Lettuce.

472 Foodborne Pathogens and Disease 5, 165-173.

473 32. Ölmez, H., Kretzschmar, U., 2009. Potential alternative disinfection methods for

474 organic fresh-cut industry for minimizing water consumption and environmental

475 impact. LWT - Food Science and Technology 42, 686-693.

476 33. Poretti, M., 1990. Quality control of water as raw material in the food industry. Food

$477 \quad$ Control 1, 79-83.

478 34. Söderström, A., Österberg, P., Lindqvist, A., Jönsson, B., Lindberg, A., Blide

479 Ulander, S., Welinder-Olsson, C., Löfdahl, S., Kaijser, B., De Jong, B.,

480 Kühlmann-Berenzon, S., Boqvist, S., Eriksson, E., Szanto, E., Andersson, S.,

481 Allestam, G., Hedenström, I., Ledet Muller, L., Andersson, Y., 2008. A Large

482 Escherichia coli O157 Outbreak in Sweden Associated with Locally Produced 
484 35. Shen, C., Luo, Y., Nou, X., Bauchan, G., Zhou, B., Wang, Q., Millner, P., 2012.

485 Enhanced Inactivation of Salmonella and Pseudomonas Biofilms on Stainless Steel

486 by Use of T-128, a Fresh-Produce Washing Aid, in Chlorinated Wash Solutions.

$487 \quad$ Applied and Environmental Microbiology 78, 6789-6798.

488 36. Van Haute, S., Sampers, I., Holvoet, K., Uyttendaele, M., 2013. Physicochemical

489 Quality and Chemical Safety of Chlorine as a Reconditioning Agent and Wash Water

490 Disinfectant for Fresh-Cut Lettuce Washing. Applied and Environmental

$491 \quad$ Microbiology 79, 2850-2861.

492 37. Van Haute, S., Uyttendaele, M., Sampers, I., 2015. Coagulation of turbidity and

493 organic matter from leafy-vegetable wash-water using chitosan to improve water

494 disinfectant stability. LWT - Food Science and Technology 64, 337-343.

495 38. WHO, 2005. Report of a Joint FAO/WHO Workshop on Fruit and Vegetables for

496 Health. (1-3 September, 2004: Kobe, Japan) World Health Organization, Geneva,

$497 \quad$ Switzerland

498 39. Zhou, B., Luo, Y., Nou, X., Millner, P., 2014. Development of an Algorithm for

499 Feed-Forward Chlorine Dosing of Lettuce Wash Operations and Correlation of

$500 \quad$ Chlorine Profile with Escherichia coli O157:H7 Inactivation. Journal of Food 
$501 \quad$ Protection 77, 558-566.

502 40. Zularisam, A.W., Ismail, A.F., Salim, R., 2006. Behaviours of natural organic matter

503 in membrane filtration for surface water treatment - a review. Desalination 194,

$504 \quad 211-231$.

505 
Table 1 Characteristics of vegetable wash water and vegetable extracts

\begin{tabular}{|c|c|c|c|c|c|c|c|c|c|}
\hline \multirow{2}{*}{ Sample } & \multicolumn{2}{|c|}{ COD (mg/L) } & \multicolumn{3}{|c|}{ Nitrogen Composition } & \multicolumn{2}{|c|}{ TOC } & \multicolumn{2}{|c|}{$\begin{array}{c}\text { UV absorbance at } \\
\text { wavelength of } 254 \mathrm{~nm}\end{array}$} \\
\hline & $\begin{array}{c}\text { Non- } \\
\text { Filtered }\end{array}$ & Filtered & $\begin{array}{l}\text { Total N } \\
(\mathrm{mg} / \mathrm{L})\end{array}$ & $\begin{array}{c}\mathrm{NO}_{3}+\mathrm{NO}_{2} \\
(\mathrm{mg} / \mathrm{L})\end{array}$ & $\begin{array}{c}\text { TKN } \\
(\mathrm{mg} / \mathrm{L})\end{array}$ & $\begin{array}{c}\text { TOC } \\
(\mathrm{mg} / \mathrm{L})\end{array}$ & $\begin{array}{c}\text { DOC } \\
(\mathrm{mg} / \mathrm{L})\end{array}$ & $\begin{array}{c}\text { Non- } \\
\text { Filtered }\end{array}$ & Filtered \\
\hline Iceberg Lettuce Extracts & 38100 & 34400 & 708 & 293 & 415 & 13200 & 12600 & 24.9 & 18.1 \\
\hline $\begin{array}{l}\text { Shredded Iceberg Lettuce } \\
\text { Wash }\end{array}$ & 2420 & 2420 & 39.9 & 16.9 & 23 & 686 & 640 & 1.19 & 0.865 \\
\hline Equivalent Extract Ratio (\%) & 6.35 & 7.03 & 5.64 & 5.77 & 5.54 & 5.20 & 5.08 & 4.78 & 4.78 \\
\hline Romaine Lettuce Extracts & 34200 & 22900 & 985 & 208 & 777 & 9750 & 7760 & 60.2 & 20.8 \\
\hline $\begin{array}{l}\text { Shredded Romaine Lettuce } \\
\text { Wash }\end{array}$ & 2580 & 2420 & 43.4 & 19.5 & 24 & 692 & 690 & 2.41 & 1.73 \\
\hline Equivalent Extract Ratio (\%) & 7.54 & 10.57 & 4.41 & 9.38 & 3.09 & 7.10 & 8.89 & 4.00 & 8.34 \\
\hline Carrot Extracts & 95600 & 87800 & 664 & 322 & 342 & 29400 & 28200 & 67.6 & 42.1 \\
\hline Shredded Carrot Wash & 4830 & 4530 & 15.1 & 11.1 & 4.02 & 1930 & 1780 & 2.46 & 1.52 \\
\hline Equivalent Extract Ratio (\%) & 5.05 & 5.16 & 2.27 & 3.45 & 1.18 & 6.56 & 6.31 & 3.64 & 3.62 \\
\hline Baby Spinach Extracts & 46400 & 35900 & 2950 & 544 & 2410 & 14100 & 11200 & 143 & 86 \\
\hline Baby Spinach Wash & 94.8 & 48 & 3.17 & 0.754 & 2.42 & 11.7 & 9.9 & 0.292 & 0.166 \\
\hline Equivalent Extract Ratio (\%) & 0.20 & 0.13 & 0.11 & 0.14 & 0.10 & 0.08 & 0.09 & 0.20 & 0.19 \\
\hline
\end{tabular}


Table 1 (continued) Characteristics of vegetable wash water and vegetable extracts

\begin{tabular}{|c|c|c|c|c|c|}
\hline \multirow[b]{2}{*}{ Sample } & \multicolumn{5}{|c|}{ IC } \\
\hline & $\begin{array}{c}\text { Fluoride } \\
\left(\mathrm{F}^{*} ; \mathrm{mg} / \mathrm{L}\right)\end{array}$ & $\begin{array}{c}\text { Chloride } \\
\left(\mathrm{Cl}^{\prime} ; \mathrm{mg} / \mathrm{L}\right)\end{array}$ & $\begin{array}{c}\text { Nitrate } \\
\left(\mathrm{NO}_{3}^{-} ; \mathrm{mg} / \mathrm{L}\right)\end{array}$ & $\begin{array}{c}\text { Sulfate } \\
\left(\mathrm{SO}_{4}^{2-} ; \mathrm{mg} / \mathrm{L}\right) \\
\end{array}$ & $\begin{array}{c}\text { Phosphate } \\
\left(\mathrm{PO}_{4}{ }^{3-} ; \mathrm{mg} / \mathrm{L}\right) \\
\end{array}$ \\
\hline Iceberg Lettuce Extracts & n.d.* & 205 & 211 & 14.9 & 193 \\
\hline $\begin{array}{l}\text { Shredded Iceberg Lettuce } \\
\text { Wash }\end{array}$ & n.d.* & 15.0 & 15.2 & 1.04 & 16.3 \\
\hline Equivalent Extract Ratio (\%) & & 7.31 & 7.22 & 7.00 & 8.42 \\
\hline Romaine Lettuce Extracts & 17.6 & 324 & 253 & 17.9 & 105 \\
\hline $\begin{array}{l}\text { Shredded Romaine Lettuce } \\
\text { Wash }\end{array}$ & 4.21 & 25.8 & 17.0 & 5.16 & 20.8 \\
\hline Equivalent Extract Ratio (\%) & $23.92 * *$ & 7.96 & 6.73 & $28.83^{* *}$ & $19.85^{* *}$ \\
\hline Carrot Extracts & 70.5 & 735 & n.d.* & 149 & 741 \\
\hline Shredded Carrot wash & 5.12 & 16.6 & n.d. $*$ & 3.40 & 17.3 \\
\hline Equivalent Extract Ratio (\%) & 7.27 & 2.25 & & 2.28 & 2.34 \\
\hline Baby Spinach Extracts & n.d. $*$ & 417 & 721 & 5.96 & 306 \\
\hline Baby Spinach wash & n.d.* & 1.41 & 1.92 & 2.12 & n.d.* \\
\hline Equivalent Extract Ratio (\%) & & 0.34 & 0.27 & $35.50 * *$ & \\
\hline
\end{tabular}

*n.d.: not detected or below detection limit

** These measurements were excluded in the data analysis of Table 2. 
Table 2 The average and standard deviation of equivalent juice ratio and the equivalent volume of vegetable juice released from three fresh-cut vegetable wash waters and baby spinach wash water.

\begin{tabular}{l|lll} 
Sample & $\begin{array}{c}\text { Average of } \\
\text { Equivalent } \\
\text { Juice Ratio (\%) }\end{array}$ & $\begin{array}{c}\text { Standard } \\
\text { Deviation }\end{array}$ & $\begin{array}{c}\text { Equivalent Volume of } \\
\text { Vegetable Juice Released } \\
\text { (mL/Kg) }\end{array}$ \\
\hline $\begin{array}{l}\text { Shredded Iceberg } \\
\text { Lettuce Wash Water }\end{array}$ & 6.16 & 1.15 & 82.1 \\
$\begin{array}{l}\text { Shredded Romaine } \\
\text { Lettuce Wash Water }\end{array}$ & 7.09 & 2.37 & 94.5 \\
$\begin{array}{l}\text { Shredded Carrot } \\
\text { Wash Water }\end{array}$ & 3.95 & 1.94 & 158 \\
Baby Spinach Wash & & & 2.26 \\
Water & 0.17 & 0.08 &
\end{tabular}


Table 3. Correlations between chemical properties of vegetable washing water and chlorine demand at 90 minutes

\begin{tabular}{c|c} 
Parameters & $\mathbf{R}^{\mathbf{2}}$ \\
\hline $\mathrm{COD}$ & 0.99 \\
Total N & -0.15 \\
$\mathrm{NO}_{3}{ }^{-}+\mathrm{NO}_{2}{ }^{-}$ & 0.19 \\
$\mathrm{TKN}$ & -0.31 \\
$\mathrm{TOC}$ & 0.89 \\
$\mathrm{UV}_{254}$ absorbance & 0.73 \\
$\mathrm{Cl}^{-}$ & 0.36 \\
$\mathrm{NO}_{3}{ }^{-}$ & -0.35 \\
$\mathrm{SO}_{4}{ }^{-}$ & 0.45 \\
$\mathrm{PO}_{4}{ }^{3-}$ & 0.63
\end{tabular}


Figure 1
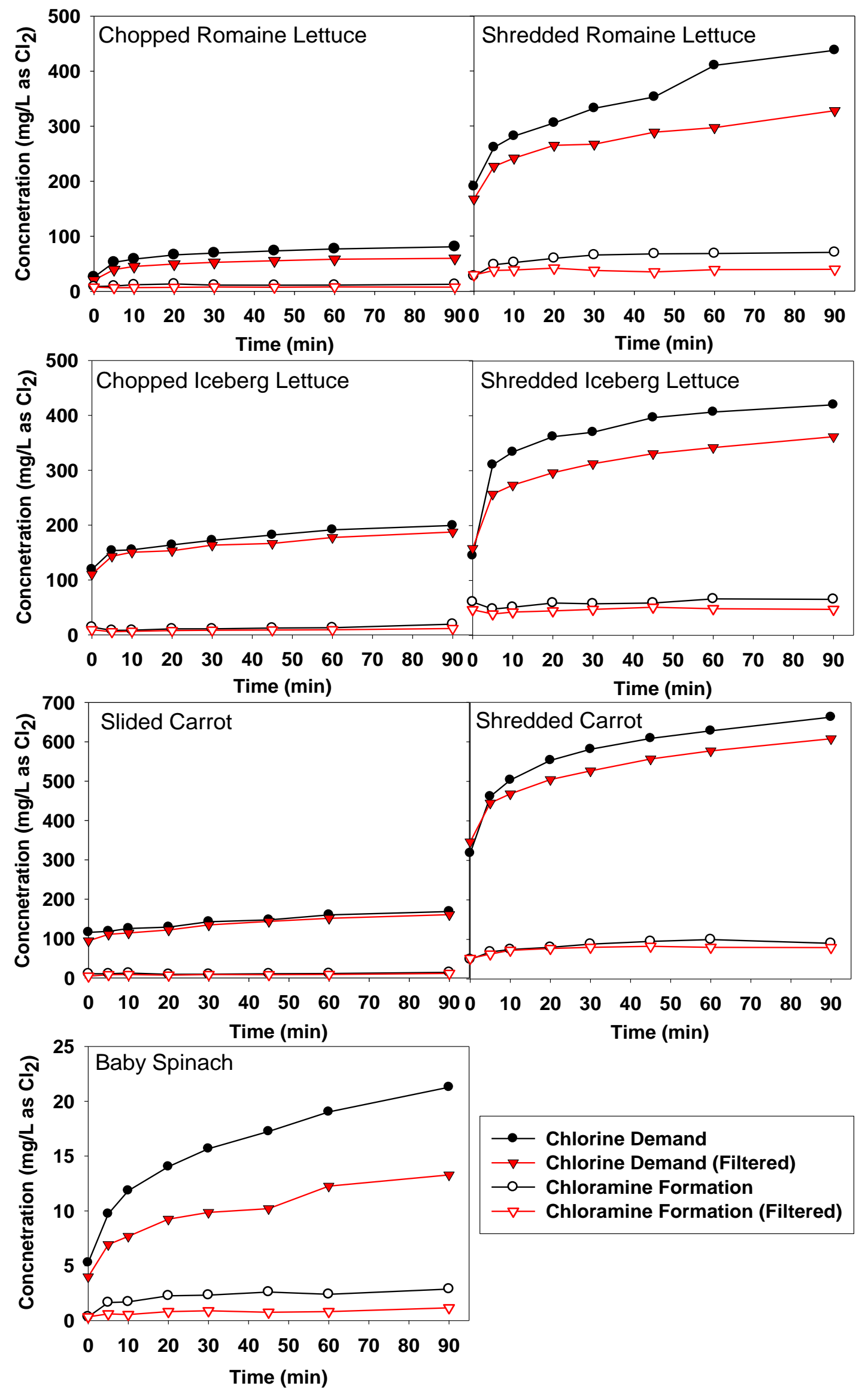

$\rightarrow$ Chlorine Demand

$\rightarrow$ Chlorine Demand (Filtered)

- - Chloramine Formation

$\rightarrow-$ Chloramine Formation (Filtered)

Figure 1. Kinetics of chlorine demand and chloramine formation over 90 minute contact time from chlorination of fresh-cut vegetable wash waters with or without filtration. 


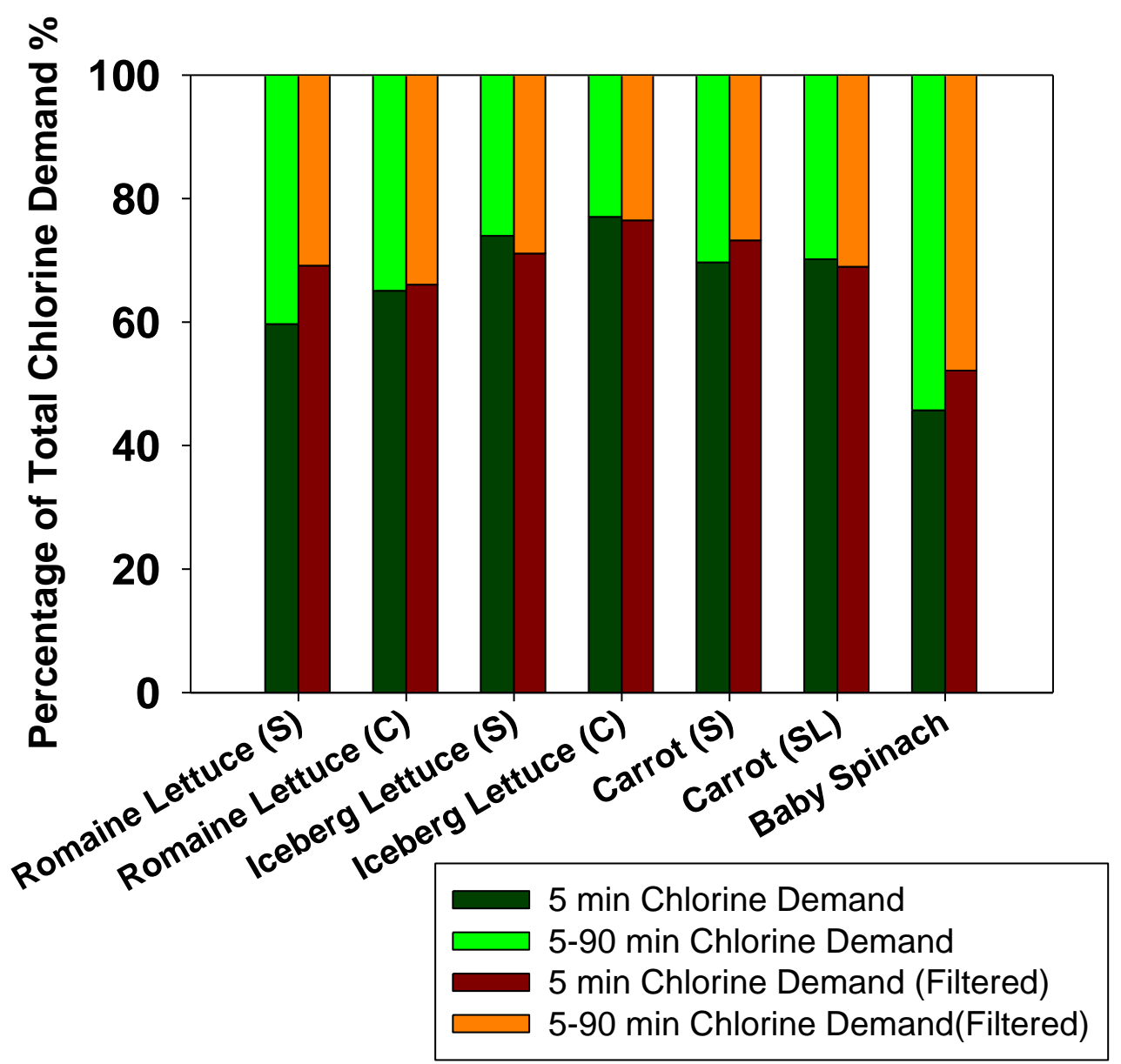

Figure 2. The distribution of time-dependent chlorine demand of vegetable wash waters with or without filtration over 90 minutes contact time. $\mathrm{S}=$ shredded; $\mathrm{C}=$ chopped; $\mathrm{SL}=$ sliced 


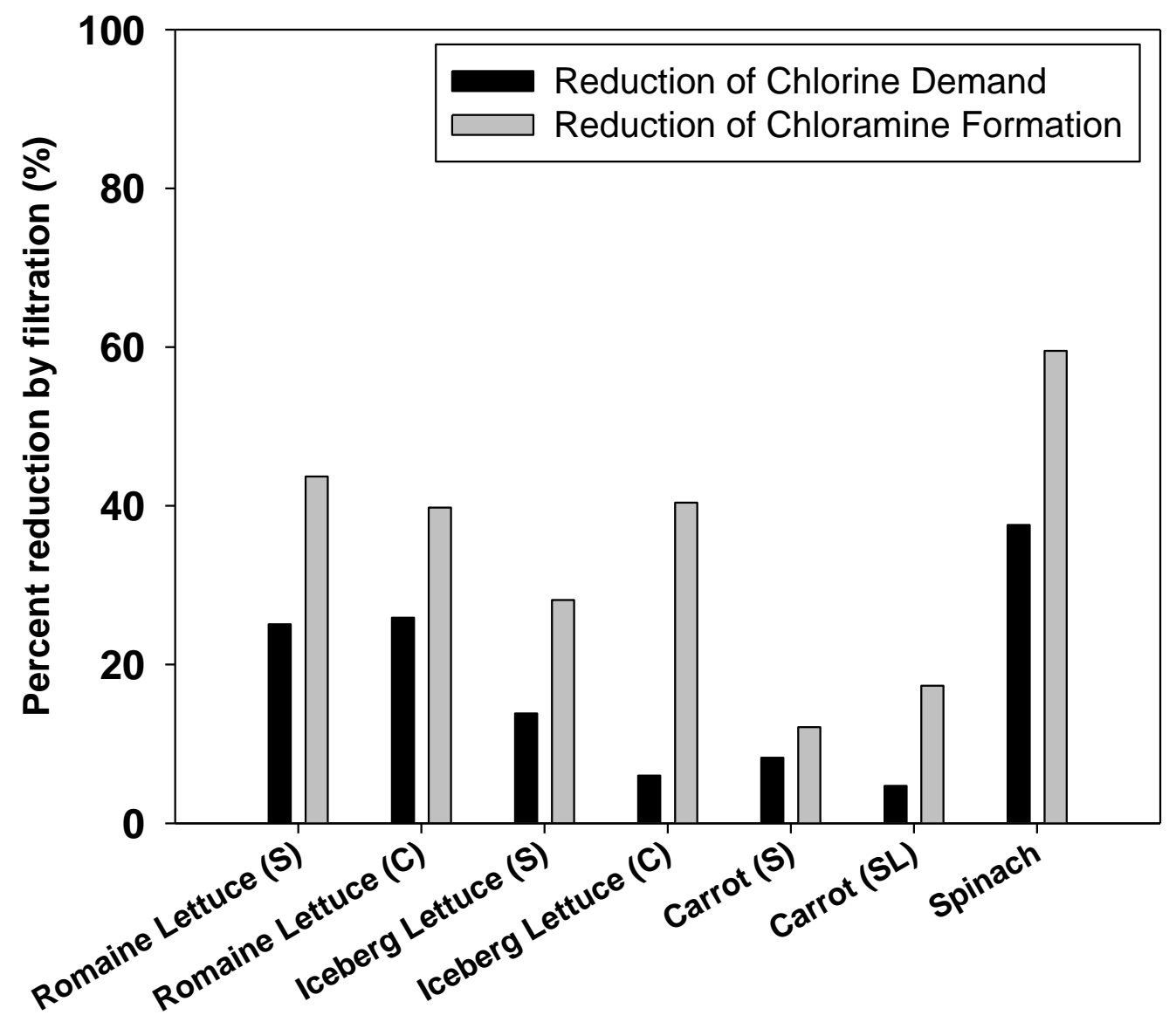

Figure 3 The effects of filtration on reduction of chlorine demand and chloramines formation over 90 minutes in four vegetable washing waters. $\mathrm{S}=$ shredded; $\mathrm{C}$ $=$ chopped; $\mathrm{SL}=$ sliced 


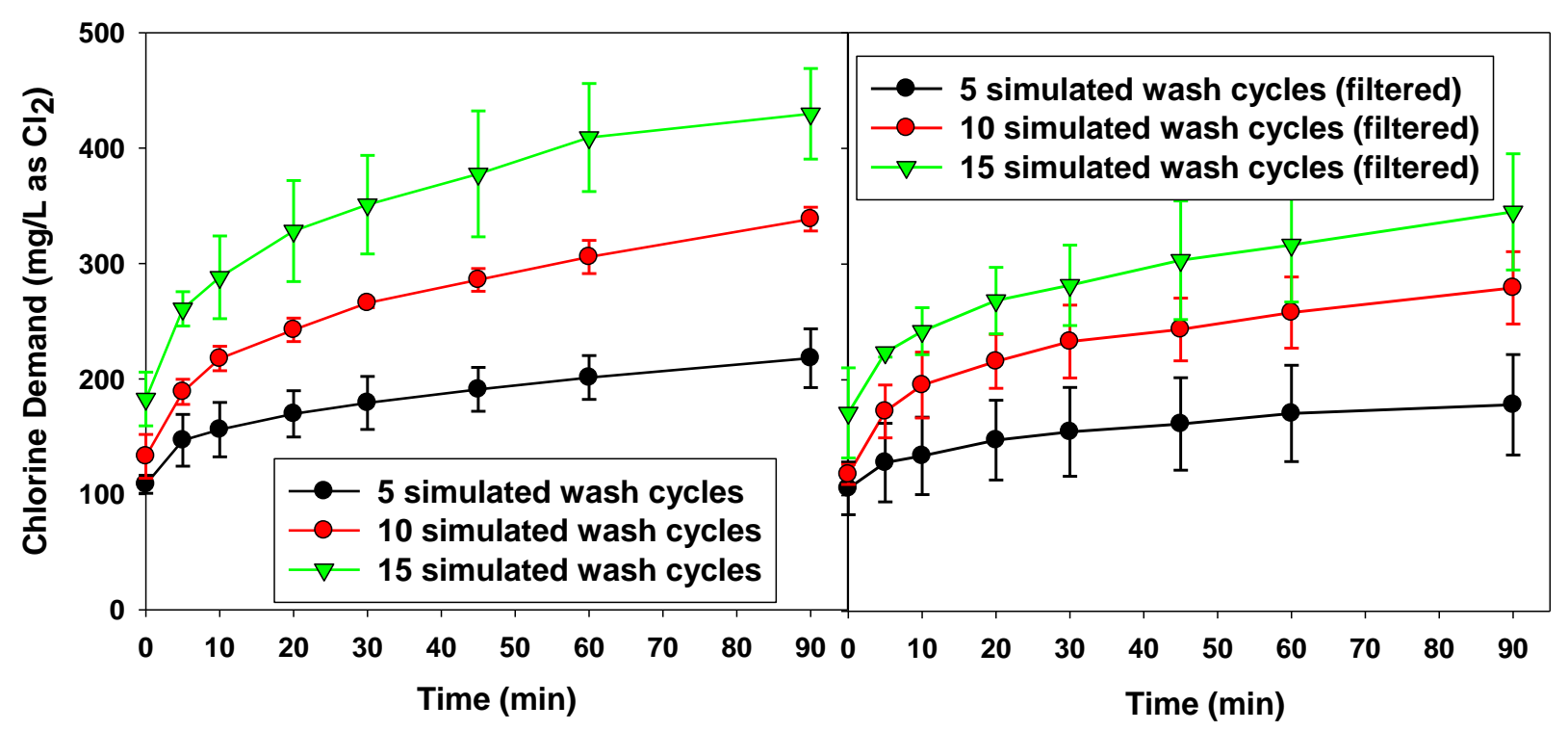

(a)

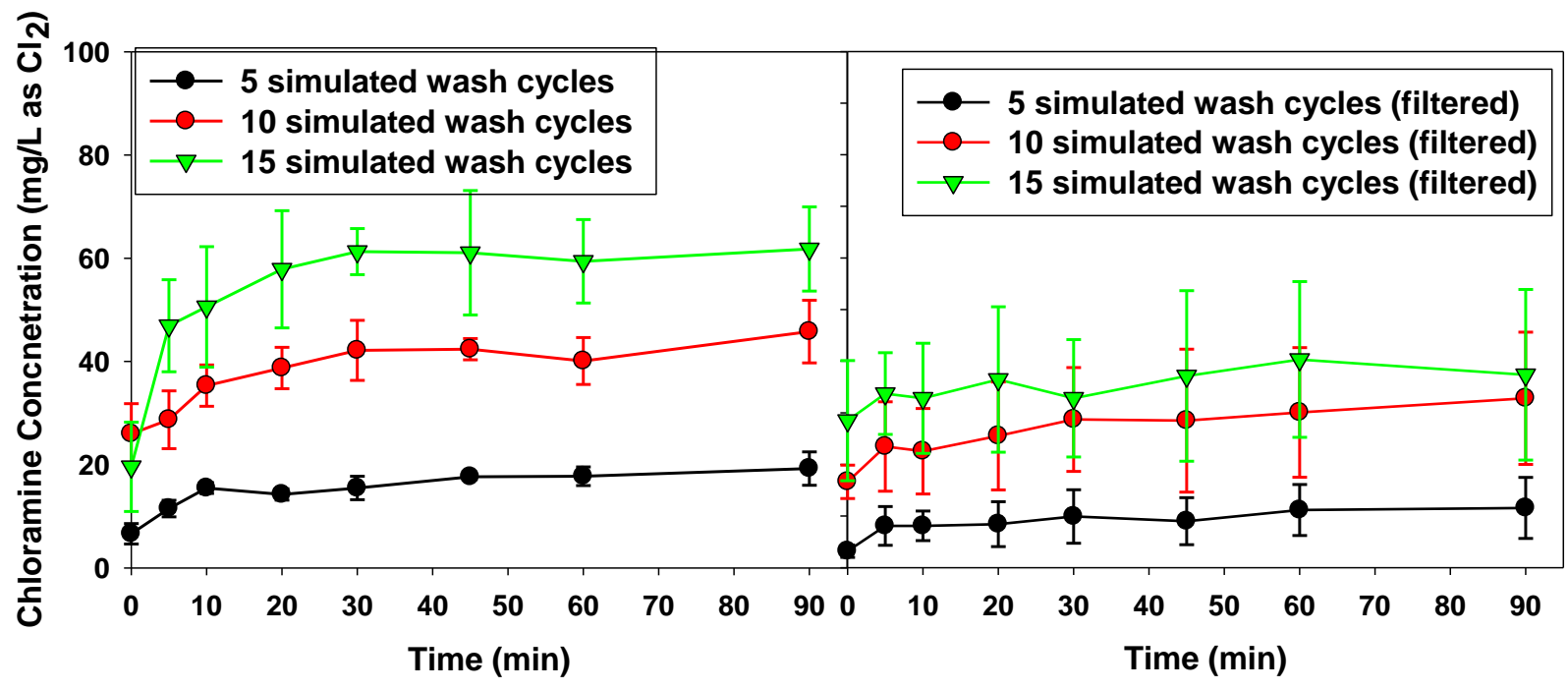

(b)

Figure 4. (a) Chlorine demand kinetics and (b) chloramines formation over 90 minutes from chlorination of shredded romaine lettuce wash water after 5 simulated wash cycles, 10 simulated wash cycles, and 15 simulated wash cycles with and without filtration. 

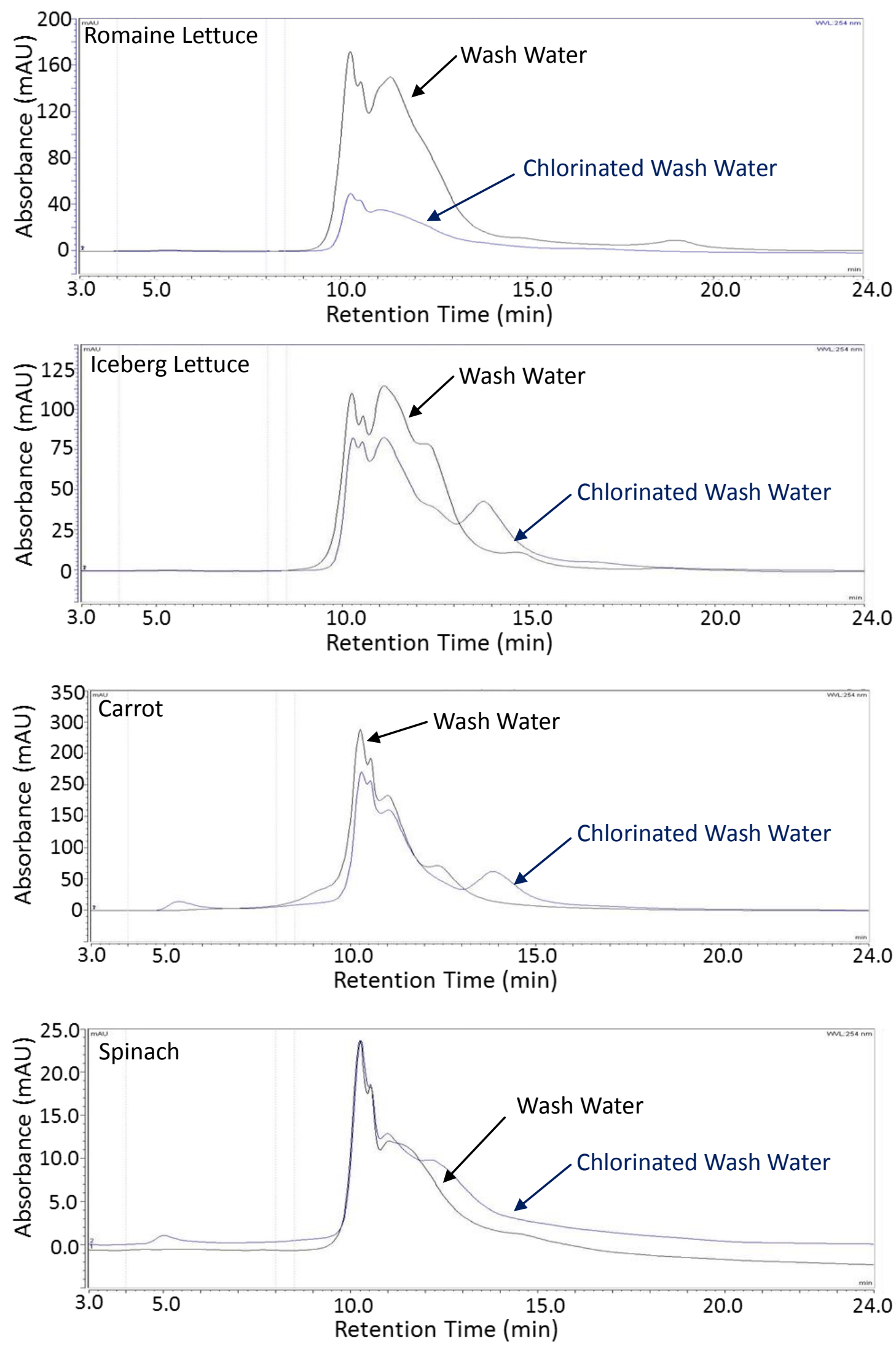

Figure 5. The HPLC-SEC chromatographs of four vegetable wash waters before (black line) and after (blue line) chlorination at wavelength of $254 \mathrm{~nm}$. 